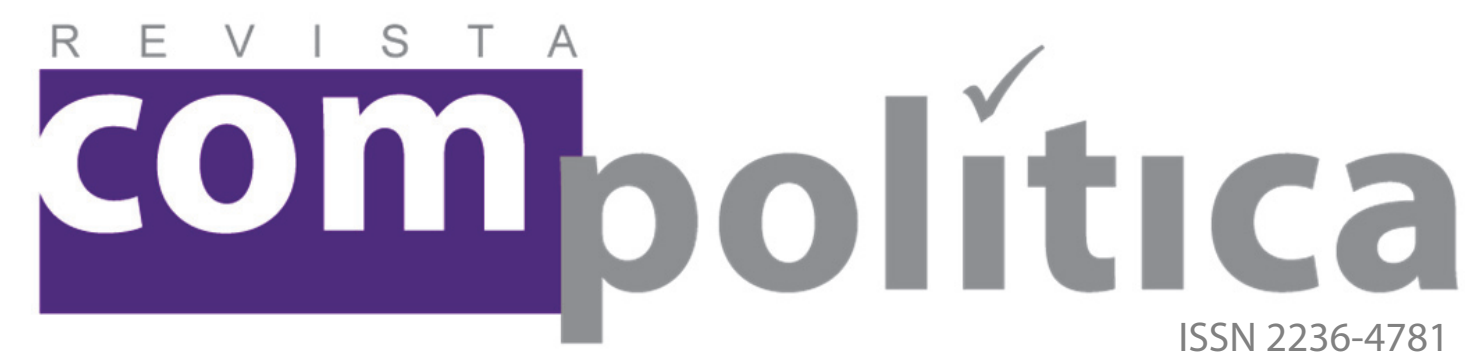

BATISTA, Jandré Corrêa

Doutorando em Comunicação e Informação pela Universidade

Federal do Rio Grande do Sul (UFRGS).

<jandrecb@gmail.com>

\title{
Apropriações ativistas em sites de redes sociais: um olhar sobre as dinâmicas da ação coletiva no movimento \#forasarney
}

RESUMO

O presente trabalho versa sobre as apropriações do microblog Twitter (twitter.com) para fins ativistas. Para tanto, pretende-se apresentar a análise da intencionalidade (THOMPSON, 2000) das formas simbólicas percebidas nas apropriações do site de rede sociais (BOYD e ELISSON, 2006) no caso \#forasarney. A partir da Hermenêutica de Profundidade de Thompson (2000), o estudo interpreta cinco intencionalidades: convocacional, informacional, divulgacional, retroalimentar e conversacional. As mensagens foram classificadas a partir da análise categorial da análise de conteúdo de Bardin (2009), interpretadas de acordo com as suas finalidades.

Palavras-chave: ação coletiva; ativismo; Twitter.

\section{ABSTRACT}

This paper aims to study the appropriation of Twitter (twitter.com) for activists ends. To this end, we intend to present the analysis of intentionality (Thompson, 2000) of symbolic forms perceived in the appropriations social networking site (Boyd and Elisson, 2006) in case \# forasarney. From the Depth Hermeneutics of Thompson (2000), the study interprets five intentions: convocacional, informational, divulgacional, feedback and conversational. The messages were classified by analyzing categorical content analysis of Bardin (2009), interpreted in accordance with its purposes.

Keywords: collective action; activism; Twitter. 


\section{Apropriações ativistas em sites de redes sociais: um olhar sobre as dinâmicas da ação coletiva no movimento \#forasarney}

\section{[Activists' appropriations in social networking websites: the collective action dynamics in \#forasarney]}

BATISTA, Jandré Corrêa

A o refletir sobre a viabilidade de uma ação coletiva, isto é, ações tomadas em conjunto com um objetivo em comum, diversos autores - tanto clássicos (cf. OLSON, 1965) quanto contemporâneos (cf. FLANAGIN et al., 2006) ressaltam o papel essencial do elemento comunicação na estrutura de um movimento. Em A lógica da ação coletiva, obra que marcou o paradigma teórico denominado Teoria da Mobilização dos Recursos (MR) (cf. GOHN, 1997), por exemplo, Olson (1965), tendo como base o contexto comunicacional da época, trata das dificuldades para a emergência de uma ação coletiva no âmbito de grupos de grandes dimensões. Problemas em termos de coordenação, organização, reconhecimento coletivo e oportunismo (free-rider) são citados pelo autor como impeditivos para o sucesso de uma ação coletiva. As razões estão centradas em um eixo: as dificuldades de comunicação nos grupos de maiores dimensões. Grupos menores, diferentemente, possuem mais facilidade de organização e coordenação, pois dispõem de menor custo para estabelecer comunicação entre seus integrantes.

Considerando a ação coletiva como essencialmente comunicacional, diversas transformações das formas de atuação política são percebidas no contexto contemporâneo, resultantes, em parte, da ampliação das capacidades comunicativas dos sujeitos. A apropriação da Internet para o ativismo é citada, nessa linha de pensamento, como a responsável pelo declínio do individualismo, contrariando o avanço da lógica do modelo liberal nas relações humanas (cf. POSTMES e BRUNSTING, 2002).

$\mathrm{Na}$ perspectiva dos novos movimentos sociais, destaca-se a transferência dos lugares de se fazer política como uma característica da contemporaneidade. Em vez de se registrar a articulação de sujeitos em organizações formais, espaços antes alheios à política tendem a ser apropriados para esse fim (cf. PRUDÊNCIO, 2006). Em 140 caracteres ou menos, o microblog Twitter é um desses exemplos. Movimentos recentes na esfera interacional, 
como \#iranelection (2009), \#occupy (2011) e as mobilizações na chamada Primavera Árabe (2011) ilustram essa realidade. No Brasil, em 2009, o movimento \#forasarney foi uma das ações coletivas que se apropriou do site de redes sociais para causas ativistas.

Assim, com base no caso em tela, o presente artigo pretende refletir sobre como se deram as práticas ativistas no microblog Twitter, tentando compreender de que maneira o site de redes sociais é apropriado para o ativismo. Para tanto, adota-se a Hermenêutica de Profundidade, de Thompson (2000), como método. A técnica da análise de conteúdo de Bardin (2009) é aplicada na segunda categoria de análise prevista por Thompson (1998): a análise formal discursiva. Num primeiro momento, apresenta-se o conceito operacional de ativismo (cf. JORDAN, 2002) e a tipologia conceitual a priori sobre os usos ativistas na Internet (cf. VEGH, 2002). Após, faz-se uma introdução sobre o método Hermenêutica de Profundidade (THOMPSON, 2000) para, então, chegarmos à aplicação do método sobre a realidade em estudo: a mobilização \#forasarney no Twitter.

\section{Do Ativismo}

O ativismo pode ser entendido como uma ação política indireta não institucionalizada (cf. ASSIS, 2006). Por "não-institucionalizada" interpreta-se, na perspectiva dos novos movimentos sociais, as ações políticas não coordenadas pelas organizações tradicionalmente presentes nas dinâmicas da ação coletiva, como os sindicatos e os partidos políticos. Uma ação política direta é entendida pelos processos políticos formais de participação popular, como o ato de votar, ao passo que a indireta se define pelas manifestações, pelas formas de protesto como greve, subversão, boicote etc., ou seja, por “(...) qualquer ação positiva (fazer algo) que tenha implicações concretas, e geralmente imediatas, sobre seus alvos" (ASSIS, 2006, p. 14).

Assis (2006) sugere que a popularização do termo ativismo teria se dado, provavelmente, como uma estratégia de desvinculação dos atores sociais engajados politicamente em relação aos estereótipos de "revolucionário" e "radical". Em defesa de uma concepção das ações coletivas políticas como "socialmente ativas" e "responsáveis", a ideia de ativismo traz a passagem do indivíduo comum ao entendimento de cidadão (PRUDÊNCIO, 2006). A noção de ativismo, assim, afasta-se das formas concretas da ação coletiva. O protesto criativo contemporâneo traria cada vez mais elementos do lúdico (cf. PERANI, 2007) para a transmissão de seus enquadramentos políticos à sociedade. O termo ativismo distancia-se, assim, da imagem relacionada às ações extremistas, violentas e armamentistas que buscam tomar o poder por meio da força.

Nessa linha de pensamento, uma perspectiva operacional sobre o ativismo pode ser destacada no trabalho de Tim Jordan (2002). 
Adotado aqui como conceito operacional, o autor defende como "ativismo político" as ações coletivas que demandam transgressão e solidariedade. Por "transgressão", entende-se a prática de oposição a certa condição social, com vistas a sua transformação. Por "solidariedade", afirma-se o sentido coletivo de suporte mútuo em busca dessa transgressão. Os dois aspectos formam o pressuposto essencial ao ativismo: o caráter coletivo e solidário orientado à mudança social.

Pensando o ativismo no contexto comunicacional contemporâneo, Vegh (2002) investigou as aplicações do ativismo on-line e construiu um modelo de categorização sobre as apropriações ativistas da Internet. A partir da interpretação dos tipos de participação política na Internet e de como se dá o fluxo de informação por esse meio, as formas de ativismo foram classificadas pelo autor em três áreas: awareness/advocacy (conscientização/promoção a respeito de um tema ou causa), action/reaction (ação/reação), organization/mobilization (organização/mobilização).

$\mathrm{Na}$ primeira categoria, situam-se as ações coletivas que se dedicam à difusão de conteúdos, especialmente notícias, para públicos internos e externos. Essas informações possuem um enquadramento conforme as perspectivas do movimento. A intenção é promover uma causa a partir de um enquadramento específico, evidenciando a relevância desses temas à sociedade. Na segunda categoria, organização/mobilização, Vegh (2002) enquadrou as convocações à ação coletiva, on-line e off-line, bem como as possibilitadas por softwares e dispositivos de "bombardeamento" de mensagens ou de "ataque" a websites e servidores. Finalmente, a terceira categoria, ação/reação, agrupa as ações que buscam a subversão às versões oficiais das instituições envolvidas e da mídia de referência acerca das ações coletivas. Alguns exemplos marcantes desse tipo de ação podem ser percebidos já nas reações da mobilização de Seattle, em 1999, e no movimento Zapatista, também na década de 1990.

\section{Do Método}

Thompson (2000), em um percurso sobre a utilização do conceito de cultura e de sua aplicação na análise dos fenômenos culturais, apresenta um panorama, dividido em quatro momentos, para elucidar as características que devem ser assumidas no estudo dos fenômenos culturais. Após esse itinerário, o autor propõe uma concepção estrutural de cultura, que levaria em conta, então, os fenômenos socioculturais "como formas simbólicas em contextos estruturados; e a análise cultural (...) como o estudo da constituição significativa e da contextualização social das formas simbólicas" (THOMPSON, 2000, p. 166). O autor propõe que o estudo das formas simbólicas seja articulado a uma abordagem metodológica específica, que privilegie os processos de interpretação, que descreve como 
Hermenêutica de Profundidade (HP). Essa opção metodológica evidencia o objeto de análise como uma teia de significados que demanda processos de interpretação.

Para a perspectiva da Hermenêutica de Profundidade, o autor estabelece três etapas de investigação: (a) análise sócio-histórica, (b) análise formal ou discursiva e (c) interpretação/reinterpretação. A primeira leva em consideração que as formas simbólicas são produzidas, difundidas e assimiladas em um dado contexto sóciohistórico. A intenção dessa etapa da pesquisa, segundo Thompson (2000), é reconstruir a conjuntura social que oportunizou a produção, circulação e a recepção das formas simbólicas. Assim, uma etapa importante dessa primeira análise é dedicada à descrição das condições espaço-temporais de produção e recepção das formas simbólicas. Também são levados em conta, na análise sócio-histórica, três outros níveis de abordagem: os campos de interação, as instituições sociais e os meios técnicos de construção e transmissão das mensagens.

As formas simbólicas possuem uma estrutura complexa: algo é dito a alguém com uma determinada finalidade. Essa característica, segundo Thompson (2000), exigirá a segunda etapa de estudo da HP: (b) a análise formal ou discursiva. A análise formal-discursiva está interessada na organização interna das formas simbólicas, suas características estruturais, padrões e relações de poder. Para o autor, essa etapa pode ser de diferentes técnicas de pesquisa, como a análise discursiva, a análise da argumentação, análise da conversação, análise semiótica etc.

A terceira etapa da Hermenêutica de Profundidade (HP) consiste no processo de interpretação/reinterpretação das formas simbólicas. Nesse estágio, a interpretação/reinterpretação será facilitada pela análise formal-discursiva, mas se apresenta de forma distinta. É um processo novo de pensamento, de síntese, que visa (re)intrepretar o caráter transcendente das formas simbólicas, tendo como recursos a análise sócio-histórica e a análise formal ou discursiva.

Para a segunda etapa da Hermenêutica de Profundidade de Thompson (2000), a análise formal-discursiva, utilizar-se-á como técnica de pesquisa para a análise categorial da análise de conteúdo de Bardin (2009). Tal técnica se baseia na divisão do texto em unidades (as categorias), a partir de agrupamentos sistemáticos. A técnica da análise de conteúdo exige três fases: a escolha das unidades que serão analisadas (o recorte de pesquisa), a escolha das regras de seleção e a escolha das categorias (classificação e agrupamento). "Qualquer comunicação, isto é, qualquer transporte de significações de um emissor para um receptor controlado ou não por este deveria poder ser escrito, decifrado pelas técnicas da análise de conteúdo" (BARDIN, 2009, p. 28).

\section{Das Análises}




\subsection{Análise Sócio-Histórica}

As denúncias de irregularidades no Senado Federal, a partir de junho de 2009, ocasionaram uma série de manifestações políticas contra a permanência do então presidente da Casa, o senador José Sarney (PMDB). A política dos atos secretos, ou seja, a omissão quanto à publicação de diversos atos administrativos, sejam nepotistas, sejam apenas impopulares, como a extensão de benefícios a parlamentares, foi noticiada amplamente pela mídia jornalística de referência. 0 principal beneficiado pelos atos foi o próprio presidente.

As manifestações contrárias à permanência de Sarney no cargo de Presidente da Casa encontraram espaço no microblog Twitter. Uma das estratégias utilizadas por cidadãos descontentes centrou-se na apropriação das redes sociais na Internet. $O$ site de redes sociais foi um dos meios mais utilizados na campanha que exigia a saída do senador de suas funções à frente do Congresso Nacional. $O$ movimento contou com o apoio de diversas celebridades do país.

No Twitter, foi criado o perfil @forasarney para fazer campanha contra o parlamentar. Uma das campanhas coadunadas foi a utilização da etiqueta/tag \#forasarney. Usuários eram incentivados a incluir o emblema em suas mensagens (tweets), independentemente do contexto que se referissem. Pelo número crescente de manifestantes, a intenção era dispor o tema nos Trending Topics (Temas do Momento) da ferramenta, de maneira a dar visibilidade internacional à discussão: tarefa não de todo simples, pela então minoria dos brasileiros que se utilizavam do sistema em junho de 2009 (cf. BATISTA e ZAGO, 2010).

Os serviços popularmente chamados de "microblogs" têm se caracterizado como um fenômeno relativamente novo (JAVA et al., 2007) e se tornado popularmente emergentes (RECUERO et al., 2009). Essas ferramentas definem-se normalmente pela restrição às interações entre os usuários (percebidas na forma de conversações, compartilhamento de informações, atualizações sobre as atividades cotidianas, opiniões, status pessoal etc.) ao limite de 140 caracteres. Por limitar as interações quanto à extensão das mensagens, a plataforma concede velocidade ao acesso e ao compartilhamento de informações (JAVA et al., 2007).

Ao contrário dos weblogs, portanto, que presumem a ideia de atualizações mais extensas e menos frequentes (JAVA et al., 2007), dispostas em espaços mais individualizados, a lógica dos microblogs incentiva publicações constantes (pela limitação de caracteres) e o acesso à informação gerada pelos contatos, na página pessoal do usuário, em ordem cronológica inversa. Embora o termo "microblog" esteja comumente associado aos weblogs por essas questões estruturais, os usos das duas ferramentas sugerem apropriações distintas, de modo que a plataforma "microblog" demanda uma 
complexificação conceitual mais além da vinculação à redução de “weblog" (cf. RECUERO, 2009).

Uma ferramenta de microblogging, em resumo, é uma plataforma híbrida que associa a comunicação por mensagens instantâneas às ideias de rede social e mobilidade (ORIHUELA, 2007; ZAGO, 2009). O limite de 140 caracteres é a mesma restrição ao tamanho das mensagens SMS (Short Message Service) da telefonia móvel. Dessa forma, é possível interagir nesse "espaço" por uma multiplicidade de dispositivos e meios.

O mais popular entre os microblogs, o Twitter, foi lançado em outubro de 2006 pela Obvious Corp. A ideia inicial do serviço propunha interações que respondessem à pergunta (no limite de 140 caracteres) "O que você está fazendo?" (What are you doing?). No entanto, a apropriação do sistema apontou usos distintos: $58,5 \%$ das atualizações (chamadas tweets), segundo estudo de Mischaud (2007), não se detinham a responder à questão. Os usos centrais são a publicação de opiniões e pensamentos, compartilhamento de notícias e hiperlinks e envio de mensagens para outras pessoas conhecidas pelo usuário (MISCHAUD, 2007). Além da questãopropositiva, a apropriação da ferramenta tem indicado uma reestruturação dos usos do serviço: em 2009 a pergunta-título da ferramenta foi alterada para "O que está acontecendo?" (What's happening?), institucionalizando as mudanças na forma de apropriação da ferramenta (ZAGO e BATISTA, 2011).

Por suas características, o Twitter pode ser considerado um site de redes sociais (BOYD e ELLISON, 2007). Os usuários são convidados a construir um perfil e a exibir a sua rede de contatos. As conexões no sistema são identificadas pela rede de following (seguidos) e followers (seguidores). Em "seguidos", consta a lista de atores de que o usuário recebe atualizações, e pela lista de "seguidores" os que recebem as atualizações emitidas pelo usuário. Não necessariamente recíprocas (pode-se seguir alguém e não ser seguido por este), as conexões no Twitter trazem peculiaridades às redes sociais que podem ser percebidas na ferramenta (RECUERO e ZAGO, 2009).

Por suas características naturalmente sociais, estruturais e comunicacionais, o Twitter tem sido apropriado para a consecução de ações coletivas (que não apresentam necessariamente cunho político). Movimentos recentes no Twitter ilustram como a possibilidade de acessar as ferramentas de comunicação, liberdade em emitir e receber e estar interconectado em rede confere ao indivíduo a oportunidade de "se manifestar para o mundo" (SCHIECK, 2009, p. 1) mesmo em um ambiente de opressão estatal. A história recente mostra como as redes sociais na Internet podem ser apropriadas para fins políticos em um contexto restritivo. Em 12 de junho de 2009, com a reeleição de Mahmoud Ahmadinejad no Irã, o Twitter foi uma das principais ferramentas utilizadas como forma de protesto - o movimento era guiado por alegações de fraude no processo eleitoral. A expressão dos manifestantes tornou-se visível 
inicialmente nas ruas da capital Teerã e em outras grandes cidades do país e nos sites de redes sociais, como o Facebook, Youtube e Flickr, além do próprio Twitter.

$\mathrm{Na}$ apuração dos votos, Ahmadinejad vencia a eleição com ampla maioria (64,78\% eram a ele atribuídos quando $94 \%$ dos votos já haviam sido apurados). Argumentos de que haveria fraudes na eleição levaram adiante uma série de manifestações pelo mundo (alguns países, inclusive, não reconheceram o resultado) e a situações de conflito e de cerceamento às liberdades individuais e à atuação dos meios de comunicação no Irã. Os sites de redes sociais respaldaram muitas das manifestações e colaboram com a sua coordenação e difusão, a ponto de levar o tema à deliberação internacional, mesmo com a restrição governamental aos meios de comunicação. Também foram restringidos os serviços de telefonia móvel e o site Facebook. O Twitter suspendeu a interrupção do serviço prevista para o dia 17 de junho (uma das datas do pico da emergência de manifestações no site de redes sociais) para não privar o acesso dos manifestantes ao seu principal meio de expressão (SCHIECK, 2009). Em uma perspectiva além fronteiras, o Twitter tornou-se o principal meio em que se podia ter acesso a informações sobre os protestos no Irã. As redes de televisão estavam sob a censura estatal e as redes internacionais não obtinham informações (id. ibid.).

Impulsionada pela criação de perfis no Twitter como forma de protesto, como @StopAhmadi e @IranElection, entre outras contas, a discussão foi levada pela apropriação da Internet à escala internacional. O Trending Topic \#iranelection chegou a registrar 220 mil mensagens por hora, o que significa que esse montante de mensagens era acompanhado - intencionalmente - pela etiqueta \#iranelection. Cada mensagem caracteriza uma contribuição para dar visibilidade ao tema.

No Brasil, movimentos semelhantes também foram registrados. Recentemente, em 2009, o movimento \#forasarney foi uma das respostas da sociedade à insatisfação de diversos grupos sociais com a permanência do senador José Sarney (PMDB-AP) na presidência do Senado em face às denúncias de corrupção a ele associadas. Uma das estratégias utilizadas por cidadãos descontentes foi a apropriação das redes sociais na Internet para dar vazão à questão e exigir a renúncia do senador.

\subsection{Análise formal discursiva}

Para interpretar os propósitos na produção de formas simbólicas, foram classificadas as mensagens sequenciais enviadas pela conta @forasarney no Twitter nas quatro primeiras semanas de manifestações no microblog (junho e julho de 2009), recuperadas para esta pesquisa em outubro de 2012. Tal conta foi escolhida por 
ter sido criada exclusivamente para formas de protesto contra a permanência de Sarney e pelo papel de protagonismo da rede de manifestações. Como o movimento foi mais proeminente na rede nos meses de junho, julho e agosto de 2009, escolheu-se para este momento, assim, um recorte que abarcasse a fase inicial das mobilizações: de como ela surgiu até o momento em que alcançou a estabilidade. Sob a perspectiva categorial da análise de conteúdo de Bardin (2009), as mensagens foram classificadas quanto à sua intencionalidade, em usos conversacionais (1), informacionais (2), convocacionais (3), divulgacionais (4) e retroalimentares (5).

Pelo uso convocacional, interpretam-se as mensagens que pretendiam o chamamento à ação coletiva, ou seja, as que tinham como propósito maior fazer com que os usuários protestassem contra o status quo da política brasileira, em especial os casos de corrupção que envolvessem a presidência do Senado. Essas ações se deram tanto na relação online-online quanto online-offline. Nas convocações online-online, os proponentes incentivaram que os participantes, por exemplo, dispusessem a hashtag \#forasarney em suas mensagens enviadas pelo Twitter, de modo que o protesto brasileiro alcançasse a página dos Trending Topics da ferramenta para que o movimento, como consequência, ganhasse repercussão nacional e internacional. Outras convocações online-online puderam ser percebidas, por exemplo, na organização da "passeata virtual", em que diversos usuários foram incentivados a enviar e-mails ao Senado Federal, por um período específico de tempo, para exigir a saída do presidente da casa. Na relação online-offline, a conta no Twitter foi utilizada para convocar usuários à participação em protestos presenciais em diversos pontos do país, dando subsídios à coordenação das ações coletivas. Também foram classificadas nessa categoria as mensagens que demonstravam, exclusivamente, a insatisfação generalizada dos proponentes com a situação política, reforçando o chamamento popular à ação.

\title{
@forasarney
}

Atenção tuiteiros de bom coração: o protesto forasarney em são paulo é no sábado, 11, em frente ao MASP, às $14 \mathrm{~h}$. favor ajudar a espalhar!

\author{
@forasarney \\ bom dia tuiteiros do brasil É HOJE. passeata virtual \\ \#forasarney: das 15h às 16h. mais no: \\ www.forasarney.com ajudem a espalhar!
}

Em relação ao uso informacional, foram assim interpretadas as mensagens que se apresentavam com o propósito de munir os usuários com informações sobre a situação de corrupção no Senado e sobre os acontecimentos relacionados aos casos de corrupção, ou 
ainda dando visibilidade às denúncias sobre ilegitimidades na administração pública. A maioria dessas mensagens era acompanhada da fonte da informação, normalmente weblogs de política, especializados, ou de matérias da chamada grande imprensa, comumente com os hiperlinks para as notícias veiculadas nos sites jornalísticos.

\author{
@forasarney \\ Reportagem da Folha deste domingo informa que três \\ contas secretas do Senado movimentavam mais de R\$ \\ 160 milhões. \\ @forasarney \\ Agripino, líder do DEM, pede a cabeça de Sarney via \\ Twitter! \\ http://www.estadao.com.br/noticias/nacional
}

Pelo uso retroalimentar, interpretam-se as mensagens que referiram ao sucesso da mobilização no Twitter, normalmente com citações a matérias sobre a repercussão on-line da campanha. Entende-se que a intencionalidade dessas mensagens se centrava na atribuição de mais peso e prestígio à mobilização, como estratégia para persuadir mais participantes ao movimento e manter atuantes os já envolvidos.

\footnotetext{
@forasarney

Bela manchete: PODER DAS TECLAS: Vozes do Twitter atordoam Senado, da zero.com.br de hoje, em matéria sobre o nosso movimento.Vamos espalhar!

@forasarney

ZH\# Um dos objetivos da campanha \#forasarney no Twitter é fazer com que o tema figure nos trending topics, o que aconteceu na noite de segunda.
}

Pela categoria "Divulgacionais", reuniram-se as mensagens que, além de demonstrar a insatisfação sobre a situação política brasileira, também se dedicavam à propaganda de outros espaços on-line destinados ao movimento. Essas emissões, por exemplo, destinavamse à divulgação do site da campanha forasarney.com como espaço privilegiado para coordenar os protestes on-line e off-line, para manifestar opiniões sobre o caso e se manter informado sobre os últimos acontecimentos. 
Saindo pro almoço. p/ quem ainda ñ sabe visite o novo www.forasarney.com Veja se está legal, fácil de entrar.estamos ajustando. \#forasarney

@forasarney

Tenho que sair. faz favor, visitem o www.forasarney.com vejam se gostam, se tá legal, fácil de entrar. estamos ajustando.

Por fim, como intencionalidade conversacional foram classificadas as mensagens públicas que faziam referências a outros usuários, também na forma de RT (retweet: outra apropriação social da ferramenta, quando um usuário replica para a sua rede de contatos uma mensagem transmitida por outro), saudações, solicitação de informações ou transmissão de mensagens produzidas por outras pessoas em outros "espaços".

\begin{abstract}
@forasarney
bom dia tuiteiros do brasil varonil. digito direto de porto alegre, que acordou fervida, protestando contra yeda, sarney e a corrupção.
\end{abstract}

@forasarney

e o que voces acharam das desculpas do sylvester stallone??? \#forasarney

\title{
3.3 Interpretação/Reinterpretação
}

A partir das duas análises aqui apresentadas, interpreta-se o movimento \#forasarney no Twitter como uma ação coletiva ativista. Com base no conceito operacional, extraído de Jordan (2002), a campanha \#forasarney pode ser entendida como ativismo, pois consistiu em ações que buscam uma transgressão em relação ao statu quo da política brasileira (o fim da corrupção, simbolizado pela exigência da saída do senador) através de meios de solidariedade/colaboração. A ideia de transgressão e solidariedade defendida por esse autor é intensamente encontrada no caso estudado.

Em resposta à questão de pesquisa "De que maneira o microblog é apropriado para o ativismo?", interpreta-se, no movimento \#forasarney, que a apropriação política do Twitter apresenta uma série de intencionalidades com vistas à persuasão do público à ação coletiva. As potenciais formas de organização, coordenação e negociação oferecidas pelo meio (e apropriadas para esses fins) respaldam substancialmente a expressão dos grupos sociais. 
O Twitter foi aplicado, assim, não pelos usos originalmente pensados para a ferramenta (a resposta à questão: "O que você está fazendo?"), mas, sim, na intenção de coordenar, dentro da limitação das interações a 140 caracteres, campanhas internas e externas ao site de rede social. Manifestações on-line e off-line foram propostas e coordenadas; estabeleceu-se um feed de notícias sobre o que acontece na "Casa dos Horrores" (como é citado o Senado pelos proponentes da ação) e deu-se conhecimento público às denúncias de corrupção. Uma das campanhas internas coadunadas pelo Twitter foi a utilização da etiqueta/tag \#forasarney. A partir das mensagens de contas de protesto criadas especificamente para esses fins, usuários foram incentivados a incluir o emblema "forasarney" em suas mensagens (tweets) no sistema, de modo a fazer com que o tema alcançasse uma visibilidade cada vez maior, em nível nacional e internacional. Interpreta-se, assim, que o microblog assume um papel relevante nas dinâmicas da ação coletiva, à medida que assume, principalmente, as intencionalidades informacional e convocacional. Permite-se aos usuários uma seleção dos acontecimentos de relevância coletiva, dando visibilidade às denúncias de corrupção e fazendo o chamamento à ação, tanto na esfera on-line quanto off-line, estabelecendo meios eficazes de coordenação.

Pensando na tipologia de Vegh (2002) dos usos ativistas da Internet: amobilização/organização, conscientização/promoção e ação/reação; percebe-se que a primeira categoria, mobilização/organização, poderia ser associada à classificação "convocacional" encontrada neste trabalho. A segunda, conscientização/promoção, equivale à categoria "informacional". Assemelham-se na perspectiva de levar temas de relevância pública às suas audiências. A terceira classificação de Vegh (2002), ação/reação, não foi encontrada neste trabalho. Essa categoria enquadra as mensagens de subversão às versões oficiais da mídia de referência, entre outras questões. No caso aqui estudado, as "versões oficiais" da mídia foram favoráveis ao movimento, não sendo necessária, portanto, a sua contestação. No lugar de ação/reação, encontrou-se a categoria "retroalimentar", ou seja, a ação coletiva na Internet como estratégia de pautar a mídia de referência e de fornecer um clipping das ações do grupo pelos olhares do jornalismo.

Além das categorias relacionadas, encontraram-se as categorias "divulgacional" e "conversacional". Pelo registro da intencionalidade divulgacional, interpreta-se que os movimentos em rede, ainda que se caracterizem pelo uso de uma plataforma específica, não se restringem a ela. Outros meios também são criados e/ou apropriados para os mesmos propósitos, em sentido complementar. No caso \#forasarney, além da conta no Twitter, o movimento reverberou principalmente por meio de um site criado para centralizar as informações sobre o caso e coordenar ações coletivas. Outras redes sociais também foram cogitadas pelos 
participantes, de modo a utilizar a ampla gama de recursos disponíveis para atingir o maior público possível.

Pelo caráter conversacional, revela-se como uma das estratégias de persuasão não apenas a possibilidade de comunicação na perspectiva muitos-muitos, mas também o contato direcionado entre os interagentes, favorecendo as trocas simbólicas. A partir desse panorama, percebe-se uma multiplicidade de estratégias de persuasão possível nas apropriações do site de redes sociais. A dinâmica (ou vantagem) de utilização da ferramenta para fins políticos, portanto, não está centrada apenas na possibilidade de ampliar as audiências, mas também na aproximação dos interagentes.

\section{Considerações Finais}

No presente trabalho, buscou-se interpretar como as apropriações políticas podem ser coadunadas em sites de redes sociais, especificamente no Twitter. A partir da análise do movimento \#forasarney, com base na metodologia da Hermenêutica de Profundidade de Thompson (2000), foram estudadas, em uma conta de protesto no site de redes sociais, as manifestações contrárias à permanência do então presidente do Senado Federal, José Sarney (PMDB), à frente dos trabalhos do Congresso Nacional. Propôs-se, brevemente, apresentar um panorama da intencionalidade dessas expressões significativas.

Por fim, percebe-se que outros estudos são necessários para o entendimento pleno do fenômeno simbólico, que considerem, entre outros quesitos, as demais categorias elencadas por Thompson (2000) em sua teoria estrutural da cultura. 


\section{Referências}

ASSIS, E. Táticas lúdico-midiáticas no ativismo político contemporâneo. Dissertação de mestrado. São Leopoldo, Universidade do Vale do Rio dos Sinos (Unisinos), 2006.

BARDIN, L. Análise de Conteúdo. Portugal: edições 70, 2009.

BATISTA, J.; ZAGO, G. Ativismo em redes sociais digitais: os fluxos de comunicação no caso \#forasarney. Estudos em Comunicação, n. 8, dez. 2010.

BOYD, D.; ELLISON, N. Social network sites: Definition, history, and scholarship. Journal of Computer-Mediated Communication, 13(1), article 11. 2007. <http://jcmc.indiana.edu/vol13/issue1/boyd.ellison.html>.

FLANAGIN, A. J.; STHOL, C.; BIMBER, B. Modeling the Structure of Collective Action, in "Communication Monographs", 73(1): 29-54, 2006.

GOHN, Maria da Glória. Teoria dos movimentos sociais: paradigmas clássicos e contemporâneos. São Paulo: Loyola, 1997.

JAVA, A.; SONG, X.; FININ, T.; TSENG, B. Why We Twitter: Understanding Microblogging Usage and Communities. Procedings of the Joint 9th WEBKDD, 2007. Disponível em <http://ebiquity.umbc.edu/paper/html/id/367/Why-We-TwitterUnderstanding-Microblogging-Usage-and-Communities>.

JORDAN, Tim. Activism! Direct action, hactivism and the future of society. Londres: Reaktion Books, 2002.

MISCHAUD, E. Twitter: Expressions of the Whole Self. An investigation into user appropriation of a web-based communications platform. MSc in Politics and Communication dissertation. London School of Economics and Political Science, September, 2007.

OLSON, M. The Logic of Collective Action: Public Goods and the Theory of Groups. EUA: Harvard University Press, 1 ed., 1965.

ORIHUELA, J. Twitter y el boom del microblogging. Educ.ar. Educación y TIC. 2007, on-line. Disponível em <http://portal.educ.ar/debates/educacionytic/supersitios/twitter-y-el-boom-del-microblo.php>.

PERANI, L. O lúdico no ativismo global. Revista Contemporânea (UERJ), v. 9, p. 32-45, 2007.

POSTMES, T.; BRUNSTING, S. Collective Action in the Age of Internet: Mass Communication and Online Mobilization. Social Science Computer Review, Vol. 20 n. 3. Estados Unidos: Sage Publications, 2002.

PRUDÊNCIO, K. Mídia ativista: a comunicação dos movimentos por justiça social na Internet. Tese de doutorado. Florianópolis: UFSC, 2006.

RECUERO, R. As redes sociais na Internet. Porto Alegre: Sulina, 2009.

RECUERO, R.; AMARAL, A.; MONTARDO, S. Blogs: mapeando um objeto. In: AMARAL, A.; RECUERO, R.; MONTARDO, S. (Orgs.). Blogs.com: Estudos sobre blogs e comunicação. São Paulo: Momento, 2009, v. 1, p. 27-54. 
RECUERO, R.; ZAGO, G. Em busca das "Redes que importam": Redes Sociais e Capital Social no Twitter. In: XVIII Congresso da Compós, PUC/MG, Belo Horizonte, 2009.

SCHIECK, M. Os gorjeios que ganharam o mundo ou a importância do Twitter na \#iranelection. In: XXXII Congresso Brasileiro de Ciências da Comunicação, Curitiba, 2009.

THOMPSON, J. Ideologia e cultura moderna: teoria social crítica na era dos meios de comunicação de massa. Petrópolis: Vozes, 2000.

VEGH, S. Classifying forms of online activism: the case of cyberprotests against the World Bank. In: McCAUGHEY, M.; AYERS, M. D. (Orgs.). Cyberactivism: online activism in theory and practice. New York: Routledge, 2003.

ZAGO, G. What's going on? Exploring microblogs as a tool for journalism. In: Internet Research 10.0 - Internet: Critical. Milwaukee: AoIR, 2009.

ZAGO, Gabriela; BATISTA, Jandré. Ativismo e agendamento nos Trending Topics do Twitter: o caso Wikileaks. Contemporânea (UFBA), v. 9, n. 2, 2011. 
